\title{
Crystallization and Sintering Behavior of PZT Prepared from Metal Alkoxides
}

\author{
Silvester TURSILOADI, Hiroaki IMAI and Hiroshi HIRASHIMA \\ Department of Applied Chemistry, Faculty of Science and Technology, Keio University, 3-14-1, Hiyoshi, Kohoku-ku, Yokohama-shi \\ 金属アルコキシドから調製したPZT の結晶化と焼結 \\ Silvester Tursiloadi - 今井宏明・平島 碩 \\ 慶應義塾大学理工学部応用化学科, 223 横浜市港北区日吉 3-14-1
}

223

[Received May 1, 1995; Accepted July 6, 1995]

\begin{abstract}
Powder precipitates and monolithic gels of lead zirconate-titanate (PZT) were prepared by hydrolysis of metal alkoxides in 1-propanol and acetylacetone/1propanol solutions, respectively. The as-dried precipitates and gels were amorphous. Deposition of pyrochlore and perovskite at a relatively low temperature, $450^{\circ} \mathrm{C}$, was observed for both the precipitate and gel. However, crystalline $\mathrm{PbO}$ was found in the gels heated at $300^{\circ} \mathrm{C}$. The results showed that the homogeneity of the powder precipitate was better than that of the gel. After heating at $600^{\circ} \mathrm{C}$, the diffraction peaks of only perovskite were found for both samples. Powder-compacts and gel compacts were sintered at temperatures higher than $900^{\circ} \mathrm{C}$. The shrinkage of the gel-compacts after sintering was greater than that of the powder-compacts because of its small particle size.
\end{abstract}

Key-words : Metal alkoxide, Sol-gel, Crystallization, Perovskite, Sintering, PZT

\section{Introduction}

The lead zirconate-titanate (PZT) ceramics are important members of the class of piezoelectric ceramics. ${ }^{1)}$ They are attractive materials because of their excellent electrical properties, such as high dielectric constant, high Curie temperature and high electromechanical coupling coefficient. ${ }^{2)}$ PZT ceramics with composition near the morphotropic phase boundary (MPB) ( $\mathrm{Zr} / \mathrm{Ti}$ ratio from $40 / 60$ to $65 / 35$ ) possess very good ferroelectric properties required for fast and reliable memory switching. ${ }^{3)}$ The PZT is known to have two crystalline phases: the pyrochlore phase being stable at relatively low temperature and the perovskite phase at relatively high temperature. Since the pyrochlore phase is centrosymmetric, it does not show ferroelectric properties. In order to use the PZT ceramics in electronic and electrooptic applications, the PZT ceramics must have a higher perovskite phase content because only the perovskite phase shows the excellent electrical and electrooptical properties that are needed for practical applications. Many methods of fabrication of high-quality crystalline perovskite phase PZT have been reported. Among these methods, sol-gel processing is promising for obtaining pure, homogeneous, and stoichiometric ceramics. It is also known to be a lowtemperature process and is applicable to a wide range of ceramics. Crystallization of the amorphous phase has been an interesting subject of both scientific and practical importance. ${ }^{4}$ During crystallization of sol-gel derived ceramics, a metastable or transitional phase is often observed prior to the formation of the final stable phase.5),6)

In this study, both PZT powder precipitate and gel near the morphotropic phase boundary were prepared by hydrolysis of metal alkoxides. Their crystallization and sintering behaviors have been investigated. Through the sol-gel method, low crystallization temperature of PZT was achieved.

\section{Experimental procedures}

Metal alkoxides, $\mathrm{Pb}\left(\text { iso }-\mathrm{C}_{3} \mathrm{H}_{7} \mathrm{O}\right)_{2}, \mathrm{Ti}\left(\text { iso }-\mathrm{C}_{3} \mathrm{H}_{7} \mathrm{O}\right)_{4}$ and $\mathrm{Zr}\left(n-\mathrm{C}_{4} \mathrm{H}_{9} \mathrm{O}\right)_{4}$, were used as starting materials. The total concentration of the alkoxides was $7.72 \times$ $10^{-2} \mathrm{~mol} / 1$. The molar ratio of $[\mathrm{Pb}]:[\mathrm{Ti}]:[\mathrm{Zr}]$ in the starting solutions was $1: 0.53: 0.47$. Thirteen times the theoretically required amount of $\mathrm{H}_{2} \mathrm{O}$ (1.5 $\mathrm{mol} / \mathrm{l}$ ) was used for hydrolysis. Powder precipitate was obtained by hydrolysis at $95^{\circ} \mathrm{C}$ for $2 \mathrm{~h}$ in 1 propanol solution. The powder precipitate was separated from the solution by decantation. Translucent sol was obtained by hydrolysis at room temperature in 1-propanol/acetylacetone (acac) solution. The molar ratio of [total metal alkoxides]/[acetyl-acetone] was 2 . The gelation time of the sol at room temperature was $19 \mathrm{~d}$. The powder precipitate and the gel were dried at $90^{\circ} \mathrm{C}$ for $18 \mathrm{~h}$, and were characterized by TG-DTA (Rigaku Thermal Analysis Station, TAS 100), transmission electron microscopy (TEM : JEM-2000 FX II, JEOL Ltd.), IR spectroscopy (BIO-RAD Digilab, FTS-65) and X-ray diffraction (RAD-C system, RTP 300, Rigaku Co.). X-ray diffraction measurements were also made for the powder precipitates and the gels after heat treatment at various temperatures in the range between 300 and $1000^{\circ} \mathrm{C}$. FT-IR spectral measurements were taken for the solutions placed between glass (KRS5) plates, and for the gels and powder precipitate by 
the $\mathrm{KBr}$ disk method. The chemical compositions of the samples were determined by energy dispersive X-ray spectroscopy (EDX : JEM-2000 FX II, JEOL Ltd.). The powder precipitate and pulverized gel were pressed at $4 \mathrm{MPa}$ to form disks about $1 \mathrm{~cm}$ in diameter, and heated up to $1000^{\circ} \mathrm{C}$. The shrinkage of the disks was measured.

\section{Results and discussion}

\subsection{Effect of chemical modification by} acetylacetone on crystallization

Figure 1 shows the TG-DTA curves for both the powder precipitate and the gel dried at $90^{\circ} \mathrm{C}$ for $18 \mathrm{~h}$. The results show an endothermic peak accompanied by a weight loss at about $100^{\circ} \mathrm{C}$ for the gel, but only small weight loss for the powder precipitate. A sharp exothermic peak accompanying the weight loss was observed at around $300^{\circ} \mathrm{C}$ for both samples, which was attributed to the combustion of residual organic compounds. A sharp exothermic peak accompanying the weight loss near $500^{\circ} \mathrm{C}$ for gel and a small exothermic peak at $450^{\circ} \mathrm{C}$ for powder precipitate were also observed.

Both the as-dried gel and powder precipitate were amorphous as determined by X-ray diffraction. The diffraction peaks of $\mathrm{PbO}$ were found for the gel heated at $300^{\circ} \mathrm{C}$ (Fig. 2(a)). However, the powder precipitate was amorphous up to $400^{\circ} \mathrm{C}$. After heating at $450^{\circ} \mathrm{C}$ for $2 \mathrm{~h}$, diffraction peaks of pyrochlore and perovskite phases were found for both samples (Figs. 2(a) and (b)). The powder precipitate has good homogeneity for deposition of PZT (perovskite) at the low temperature of $450^{\circ} \mathrm{C}$, without deposition of $\mathrm{PbO}, \mathrm{ZrO}_{2}$ or $\mathrm{TiO}_{2}$. On the other hand, apparently homogeneous gels were obtained from the solution with addition of acetylacetone. However, $\mathrm{PbO}$ was deposited at $300^{\circ} \mathrm{C}$. The diffraction peaks of the pyrochlore phase disappeared after heating at $600^{\circ} \mathrm{C}$ for both the powder precipitate and gel.

FT-IR spectra of $\mathrm{Zr}\left(n-\mathrm{C}_{4} \mathrm{H}_{9} \mathrm{O}\right)_{4}$ in 1-propanol/ acetylacetone solution showed absorption bands at 1532 and $1589 \mathrm{~cm}^{-1}$ (Fig. 3, A, arrows), which

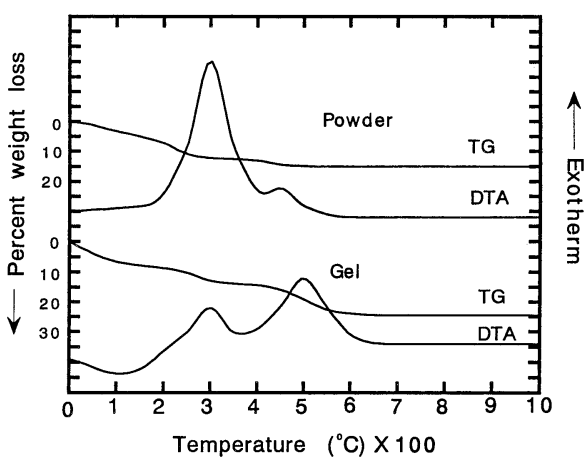

Fig. 1. TGA-DTA curves for dried PZT powder precipitate and gel at heating rate of $10^{\circ} \mathrm{C} / \mathrm{min}$.
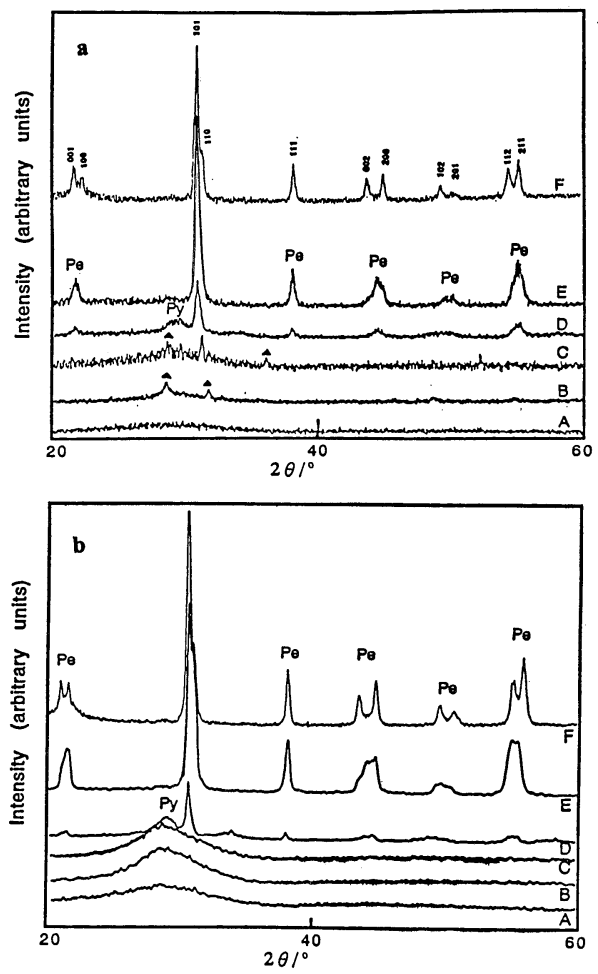

Fig. 2. X-ray diffraction patterns for PZT gel (a) and for PZT powder precipitate (b): (A) dried at $90^{\circ} \mathrm{C}$ for $18 \mathrm{~h}$, heated for $2 \mathrm{~h}$ at (B) $300^{\circ} \mathrm{C}$, (C) $400^{\circ} \mathrm{C}$, (D) $450^{\circ} \mathrm{C}$, (E) $600^{\circ} \mathrm{C}$ and (F) $1000^{\circ} \mathrm{C}$. Pe: perovskite, Py: pyrochlore and $\mathbf{\Lambda}: \mathrm{PbO}$.

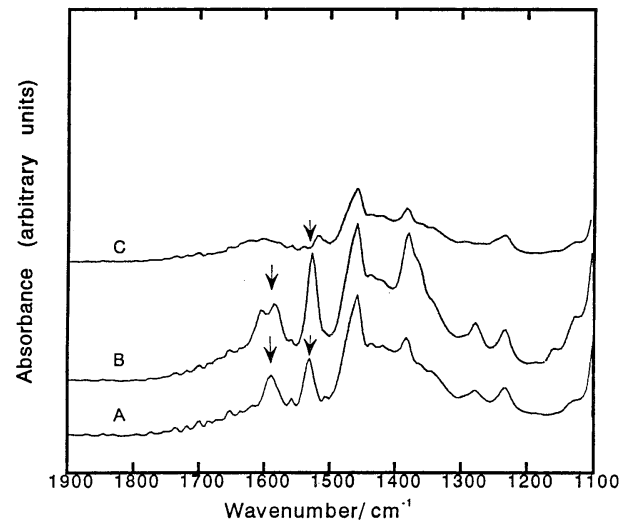

Fig. 3. Infrared spectra for (A) zirconium tetra- $n$-butoxide, (B) titanium tetra- $i$-propoxide, and (C) lead di- $i$-propoxide in acac/1propanol solutions.

were both assigned to the acac group coordinated to $\mathrm{Zr}{ }^{7)}$ The absorption bands assigned to acac coordinated to $\mathrm{Ti}$, at 1528 and $1603 \mathrm{~cm}^{-1}$ (Fig. 3, B, arrow), were also observed for $\operatorname{Ti}\left(\text { iso }-\mathrm{C}_{3} \mathrm{H}_{7} \mathrm{O}\right)_{4}$ solution. ${ }^{8)}$ However, the absorption peaks attributed to the acac group bonded to $\mathrm{Pb}$, at about 1520 and $1600 \mathrm{~cm}^{-1}$, were very weak (Fig. 3, C, arrow). The chelate complexes of metals have stronger bonding than metal alkoxides, and thus the modified metal alkoxides are more stable than the unmodified metal 
alkoxides. These results show that the chemical modification with acetylacetone retarded the hydrolysis of Ti- and $\mathrm{Zr}$-alkoxide resulting in gelation, but not the hydrolysis of $\mathrm{Pb}$-alkoxide, which was not appreciably modified by acetylacetone. Thus, the gel is inhomogeneous at the molecular level in comparison with the powder precipitate, resulting in precipitation of $\mathrm{PbO}$ at low temperatures.

The molar ratios of $[\mathrm{Pb}]:[\mathrm{Ti}]:[\mathrm{Zr}]$ in the gel and the powder precipitate heated at $600^{\circ} \mathrm{C}$, determined by EDX, are $1: 0.56: 0.47$ and $1: 0.41: 0.37$, respectively. Chemical composition of the starting solutions was the same for the gel and the powder. The gel formed from all the substances of starting solution. Therefore, the composition of the gel is almost the same as that of the starting solution. On the other hand, the powder precipitate which was separated from the solution by decantation does not contain all of the cations in the starting solution. Thus, the chemical composition of the powder after heating at $600^{\circ} \mathrm{C}$ is slightly different from the chemical composition of the starting solution, although homogeneity of the powder precipitate seems to be better than that of the gel.

\subsection{Sintering behaviors}

TEM micrographs show that particle size of the gel, $2-5 \mathrm{~nm}$ in diameter, is smaller than that of the powder precipitate, 5-10 nm in diameter. Granular agglomerates were observed for the powder precipitates (Fig. 4). The densities of the green gel and powder compact were approximately 2.9 and $2.7 \mathrm{~g} / \mathrm{cm}^{3}$, respectively. The green compact was heated at a rate of $10^{\circ} \mathrm{C} / \mathrm{min}$ and held at various tem-
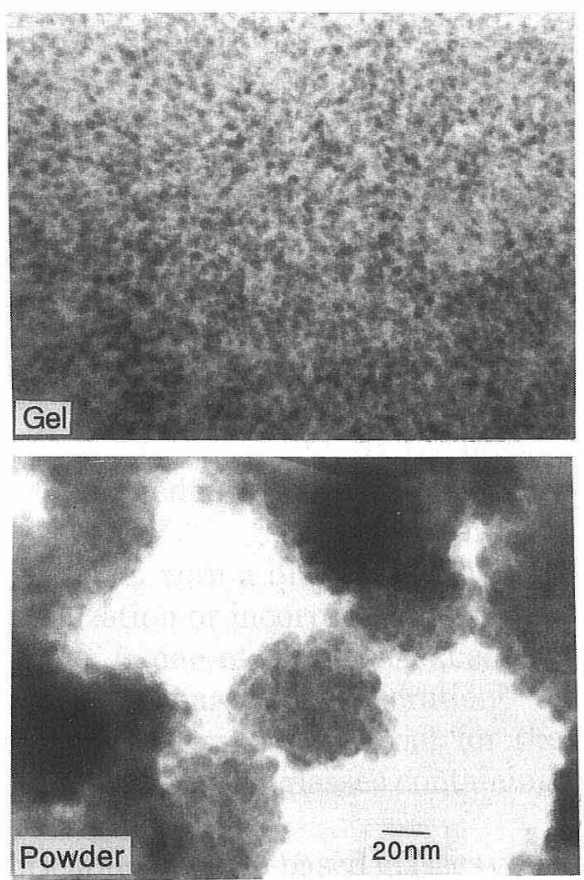

Fig. 4. TEM micrograph of PZT gel and powder precipitate after aging at room temperature for several days.
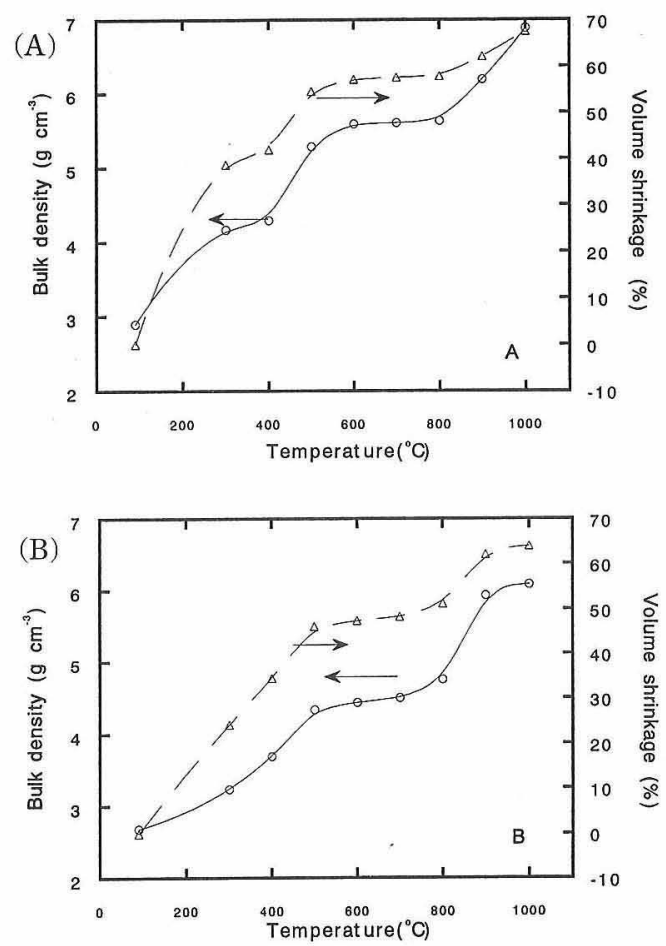

Fig. 5. Volumetric shrinkage and bulk density as a function of heating temperature for PZT gel (A), and for PZT powder precipitate $(\mathrm{B})$.

peratures in the range from 100 to $1000^{\circ} \mathrm{C}$ for 30 min. Significant increases in density were observed for the gel compact in the temperature ranges of $100-300^{\circ} \mathrm{C}$ and $400-500^{\circ} \mathrm{C}$. An increase in density was observed for the powder compact during heating to $500^{\circ} \mathrm{C}$. After heating at $500^{\circ} \mathrm{C}$, the bulk density of the gel compact was about $20 \%$ higher than that of the powder compact (Figs. 5(A) and (B)). At temperatures higher than $900^{\circ} \mathrm{C}$, shrinkage due to sintering was observed for both samples. After heating at $1000^{\circ} \mathrm{C}$, the bulk densities of the gel and the powder compact became 6.9 and $6.1 \mathrm{~g} / \mathrm{cm}^{3}$, i.e., 86 and $76 \%$ of the theoretical density, ${ }^{9)}$ respectively. The shrinkage at temperatures lower than $500^{\circ} \mathrm{C}$ is attributed to the crystallization and removal of residual organics. The higher bulk density of the sintered gel may be attributed to the small particle size, as observed by TEM.

\section{Conclusions}

(1) Powder precipitates and monolithic gels of PZT were obtained by hydrolysis of metal alkoxides in 1-propanol and acac/1-propanol solution, respectively.

(2) Both of the as-dried products were amorphous. The homogeneity of the powder precipitate was better than that of the gel, and the deposition of perovskite PZT was found at a low temperature, $450^{\circ} \mathrm{C}$. 
(3) The sintered gel-compact has higher bulk density than the sintered powder-compact, because of its smaller particle size.

\section{References}

1) A. I. Kingon, P. J. Terblanche and J. B. Clark, Materials Science and Engineering, 71, 391-97 (1985).

2) T. Fukui, C. Sakurai and M. Okuyama, J. Mater. Res., 7, 79194 (1992).

3) C. K. Kwok and S.B. Desu, J. Mater. Res., 8, 339-44 (1993).
4) Y. Yoshikawa and K. Tsuzuki, J. Am. Ceram. Soc., 73, 31-34 (1990).

5) O. Yamaguchi and H. Mogi, J. Am. Ceram. Soc., 72, 1065-66 (1989).

6) S. R. Grucovich and J. B. Blum, Ferroelectric, 62, 189 (1985).

7) U. B. Saxena, A. K. Rai, V. K. Mathur and R. C. Mehrotra, J. Chem. Soc. $(A)$, 904-07 (1970).

8) C. J. Brinker and G. W. Scherer, "Sol-Gel Science", Academic Press (1990) pp. 52-59.

9) B. Jaffe, R. S. Roth and S. Marzullo, J. Res. Nat. Bur. Stand., 55, 239-54 (1955). 